\title{
Kisspeptin is Testosterone independent regulator of Sexual Motivation in Male Rats
}

\author{
L.A. Magarramova ${ }^{1}$, I.Y. Tissen ${ }^{1}$, A.A. Blazhenko ${ }^{1}$, A.A. Lebedev ${ }^{1}$, S.I. Loskutov², S.N. Proshin ${ }^{3, *}$ \\ ${ }^{1}$ Institute of Experimental Medicine, St. Petersburg, Russia \\ ${ }^{2}$ All-Russian Research Institute for Food Additives — Branch of V.M. Gorbatov Federal Research Center for Food Systems of RAS, St. Petersburg, Russia \\ ${ }^{3}$ St. Petersburg Medical and Social Institute, St. Petersburg, Russia
}

Received - December 22, 2021; Revision - February 13, 2022; Accepted - February 27, 2022

Available Online - February 28, 2022

DOI: http://dx.doi.org/10.18006/2022.10(1).131.134

KEYWORDS
Kisspeptin
Sexual motivation
Rats
GnRH

* Corresponding author

E-mail: psnjsn@ rambler.ru (S.N. Proshin)

Peer review under responsibility of Journal of Experimental Biology and Agricultural Sciences.

Production and Hosting by Horizon Publisher India [HPI] (http://www.horizonpublisherindia.in/).

All rights reserved.

\begin{abstract}
Kisspeptin is the peptide product of the KISS-1 gene and endogenous agonist for the Kiss1 receptor. It is well known that kisspeptin acts centrally, and stimulates the secretion of gonadoliberin $(\mathrm{GnRH})$. Further, Kisspeptin also interacts with other neuropeptides such as neurokinin B and dynorphin to regulate GnRH pulse generation and plays a key role in sexual behavior. This study aimed to evaluate the effect of kisspeptin on male rats' sexual motivation and its dependence on testosterone levels. In this study total of 50 copulation naive male Wistar rats were collected and divided into 5 groups (10 rats in each group), among these first group received only saline (control), the second group has been given $20 \mu$ g buserelin acetate (GnRH analogue), the third group has been given intranasally kisspeptin-10 (3ng), the fourth has been received intraperitoneally kisspeptin-10 (30ng) and the fifth group has been given Yoquimbine 200 $\mu \mathrm{g}$. Behavioral effects were registered in the open-field reward-proximity chamber with a female in the estrous phase of the cycle over the transparent perforated wall for 10 minutes in red light. Blood samples were collected from the tail vein after 30 minutes of the substance administration and in the collected blood samples, testosterone concentration was measured by the ELISA method. All animal groups were compared with each other by the ANOVA test and correspondent "post hoc" paired tests of NewmanKruskall- Wallis test and Dunn's test. Intranasal administration of buserelin acetate increased the concentration of testosterone but did not affect sexual motivation in rats. Further, intraperitoneal administration of Kisspeptin-10 enhances testosterone concentration and sexual motivation. While intranasal administration of kisspeptin-10 didn't enhance testosterone level but increased sexual motivation. Results of this study showed some effects of kisspeptin along with the independent regulation of steroids.
\end{abstract}

All the articles published by Journal of Experimental Biology and Agricultural Sciences are licensed under a Creative Commons Attribution-NonCommercial 4.0 International License Based on a work at www.jebas.org.

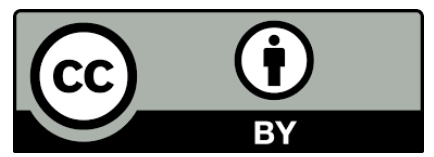




\section{Introduction}

Originally Kisspeptins are proteins encoded by the endogenous metastasis suppressor neuropeptides produced by the KISS1/kiss1 gene and are key regulators of reproductive function. Several isoforms including kisspeptin (KP)-54, KP-14, KP-13, and KP-10 exist with a common RF-amide $\mathrm{C}$ terminus (Clements et al. 2001; Kotani et al. 2001). Further, Kisspeptin is an endogenous ligand for the kisspeptin receptor (KISS1R) (Lee et al. 1999). All of the isoforms can activate the kisspeptin receptor due to a common $\mathrm{C}$ terminal decapeptide. It is well known that kisspeptin centrally acts via the kisspeptin receptor and stimulates the secretion of gonadotrophin-releasing hormone $(\mathrm{GnRH})$. Loss of kisspeptin signaling causes hypogonadotrophic hypogonadism in humans and other mammals (Silveira et al. 2010). Kisspeptin interacts with other neuropeptides such as neurokinin B and dynorphin and regulates the GnRH pulse generation (Bai et al. 2014; Wolfe et al. 2018). Adekunbi et al. (2018) and Sieme et al. (2004) suggested that Kisspeptin also plays a significant role in sexual behavior. Gonadally intact testosterone replaced male kiss1r knockout mice fail to display an olfactory partner preference despite normosmia, as evidenced by spending a comparable amount of investigatory time with male and female mice (Stephens et al. 2017). This study was carried out to evaluate the effect of kisspeptin on male rats' sexual motivation and its dependence on testosterone levels

\section{Materials and Methods}

\subsection{Experimental Animals and treatments}

For this study 50 copulation naive male Wistar rats (age 100 days, weight $250 \pm 30 \mathrm{~g}$ ) were collected and were divided into 5 groups (each group is of 10 rats). Among the formulated groups, the first group animals were intact as considered as control, while the remaining four groups were administrated with hormonal and nonhormonal regulators of sexual behavior. In the experimental group, the animals of the first group received intranasally $\mathrm{GnRH}$ analogue Buserelin acetate (Pharm sintez, Russia) @ $2 \mu \mathrm{g} / \mu \mathrm{l}$ and intraperitoneally saline. The second group received $0.15 \mu \mathrm{g} / \mu \mathrm{l}$ Kisspeptin-10 (Institute of Ultra Pure Biochemical Preparations, Russia) intranasally and saline intraperitoneally. The third group received intranasally saline and $0.15 \mu \mathrm{g} / \mu \mathrm{l}$ Kisspeptin-10 intraperitoneally. The fourth group received intranasally saline and $1 \mathrm{mg} / \mathrm{ml}$ Yoquimbine $\mathrm{HCl}$ (Zdorovie pharmaceuticals, Ukraine) intraperitoneally.

\subsection{Behavioural tests}

The Open-field reward-proximity chamber made of plexiglas was used for assessment of the appetitive behavior for sexual reward. Open-field arena $(85 \times 35 \times 50 \mathrm{~cm}$ high $)$ had a chamber over the transparent perforated wall made of Plexiglas $(15 \times 35 \times 50 \mathrm{~cm}$ high) which was mounted at one end. The front perforated wall allowed the subjects to approach and investigate (i.e., sniff) the animals (estrous female rat) in the chamber but prevented tactile contact or copulation. On the day before the appetitive behavior testing, all the subjects were habituated for $30 \mathrm{~min}$ in the openfield arena. The Male's behavior was recorded on video in the darkroom with red light for 10 minutes. The open-field and stimulus-cage were wiped clean with $3 \%$ hydrogen peroxide between subjects to eliminate olfactory cues. As the measures of sexual incentive motivation, for each animal, the time spent on sniffing the stimulus-cage (sniffing time, i.e., nose-point within the perforated wall) and latent time before were recorded.

\subsection{Testosterone assay}

Blood samples were collected from the tail after 30 minutes of the substance administration. Serum was separated with a centrifuge (8000 rpm). The samples were frozen and stored at $-80^{\circ} \mathrm{C}$ until the ELISA was performed. Testosterone concentrations in serum were measured by solid-phase ELISA using the Testosterone test system - EIA Kit (Alkor-Bio, Russia).

\subsection{Statistical Analysis}

GraphPad Prism v.5 and SPSS SigmaStat 3.0 software were used for statistical processing of the obtained quantitative data. Kolmogorov-Smirnov normality criterion was used to evaluate the correspondence of random value distributions to Gaussian ones. To compare control and experimental groups, the Wilcoxon nonparametric criterion for paired comparisons and the method of single-factor dispersion analysis with subsequent multiple intergroup comparisons by the Newman-Kales criterion was used. The data are presented as "mean $\pm \mathrm{SD}$ ".

\section{Results}

The first purpose of this study was to measure behavioral aspects of sexual motivation like the number of trying to reach the female and latent time before it. Results of the study revealed that intranasal administration of buserelin acetate didn't act on latent time before trying to reach the female $(7.9 \pm 3.5 \mathrm{sec}$. vs $8.0 \pm 3.5 \mathrm{sec}$. in control) and reduced the number of trying $(9.8 \pm 1.3 \mathrm{sec}$. vs $13.2 \pm 2.0 \mathrm{sec}$. in control). Further, intranasal and intraperitoneal administration of kisspeptin-10 reduced latent time before trying to reach the female $(3.9 \pm 1.7 \mathrm{sec}$. and $5 \pm 1.6 \mathrm{sec}$.) but only intranasal administration induced the number of trying $(19.5 \pm 3.0$ vs $14,3 \pm 2,0$ ) (Figure 1, 2). In the second step of this study, quantitative determination of testosterone in blood serum was also carried out. Buserelin acetate increase testosterone level about three times $(47.5 \pm 19.5 \mathrm{nmol} / \mathrm{ml}$ vs $14.5 \pm 6.2 \mathrm{nmol} / \mathrm{ml}$ in control). No significant differences were found between testosterone level in rats after intranasal or intraperitoneal kisspeptin-10 administration 
and control animals $(11.2 \pm 3.0 \mathrm{nmol} / \mathrm{ml}$ vs $13.1 \pm 4.0 \mathrm{nmol} / \mathrm{ml})$. Yoquimbine $\mathrm{HCl}$ also didn't enhance the testosterone level $(13.2 \pm 4.0 \mathrm{nmol} / \mathrm{ml})$ (Figure 3).

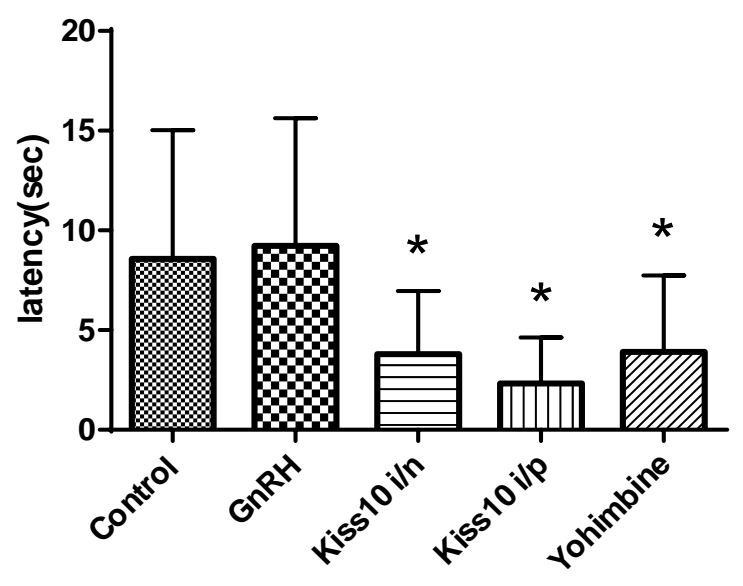

Fig 1 Latent time in sexual motivation test

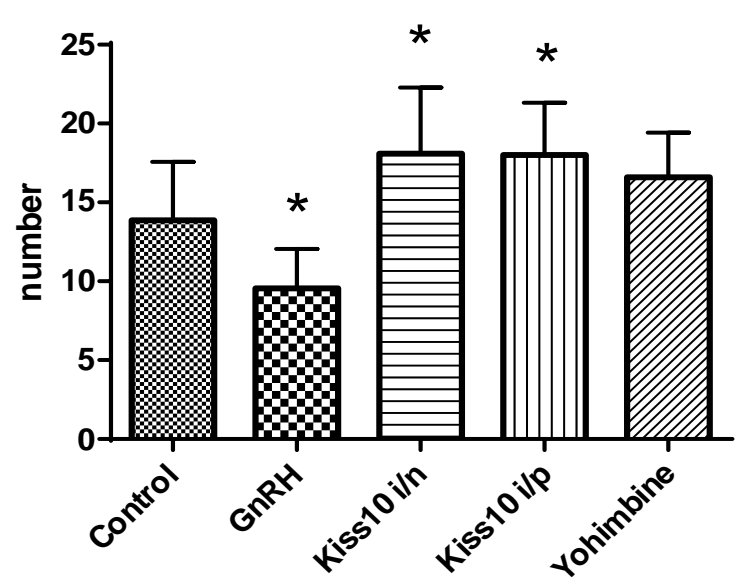

Fig 2 Number of trying to reach female in sexual motivation test

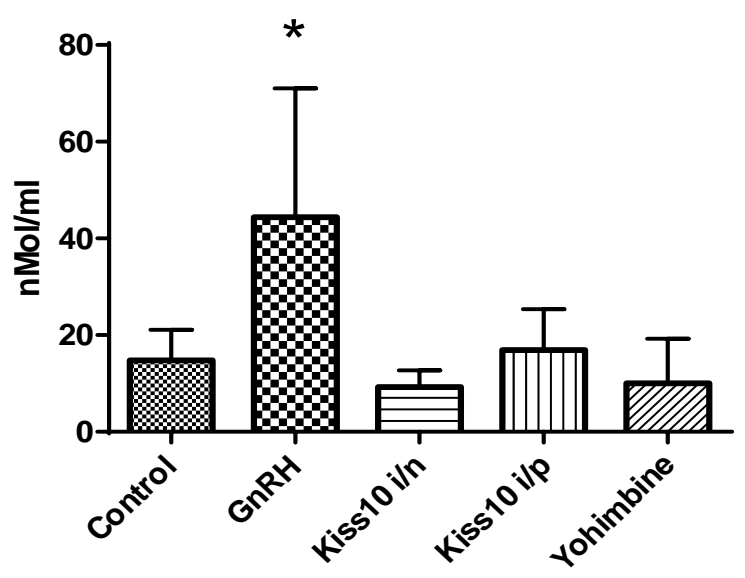

Fig 3 Testosterone in blood serum

\section{Discussions}

A strong relationship between kisspeptin, GnRH, and sexual steroids has been reported by previous researchers. The initial observations of the current study also describing the essential role of kisspeptin signaling in puberty emerged that kisspeptin neurons are also relying on steroid feedback regulation to GnRH neurons. However, till now the role of kisspeptin signaling outside of the hypothalamus was unknown. The posterodorsal medial area of the amygdala (MePD), where the kisspeptin-responsive neurons were found, is particularly associated with pheromone-related reactions, which suggests that kisspeptin may affect sexual behaviors (Lee et al. 1999). Immunohistochemistry data regarding amygdala kisspeptin neurons, identifying that they receive vasopressinergic and dopaminergic inputs (Pineda et al. 2017). It suggests interplay with key behavioral neuropeptides implicated in social behavior and motivational behavior (Meyer-Lindenberg et al. 2011; Tissen et al. 2019). Results of the study support the idea of the steroidindependent mechanism of kisspeptin effects. Low doses of buserelin acetate can induce a transitory increase of testosterone and may be helpful to stimulate libido in some mammals (Sieme et al. 2004; El-Khawaga et al. 2011).

\section{Conclusion}

Intranasal administration of buserelin acetate increased the concentration of testosterone but did not affect sexual motivation in rats. Intranasal administration of kisspeptin-10 didn't act testosterone but increased sexual motivation. Intraperitoneal administration of kisspeptin-10 acts on both testosterone concentration and sexual motivation behavior. This study has shown some effects of kisspeptin realized with the steroidindependent mechanism.

\section{Conflict of Interest}

The authors declare that they have no conflict of interest.

\section{References}

Adekunbi, D.A., Li, X.F., Lass, G., Shetty, K., et al. (2018). Kisspeptin neurones in the posterodorsal medial amygdala modulate sexual partner preference and anxiety in male mice. Journal of Neuroendocrinology, 30(3), e12572.

Bai, Y., Li, Y., Lu, Y., Liu, Z., \& Zheng, X. (2014). Complex motivated behaviors for natural rewards following a binge-like regimen of morphine administration: mixed phenotypes of anhedonia and craving after short-term withdrawal. Frontiers in Behavioral Neuroscience, 8, 23-27.

Clements, M.K., McDonald, T.P., Wang, R., Xie, G., et al. (2001). FMRFamide-related neuropeptides are agonists of the orphan G-

Journal of Experimental Biology and Agricultural Sciences http://www.jebas.org 
protein-coupled receptor GPR54. Biochemical and Biophysical Research Communications, 284, 1189-1193.

El-Khawaga, A.R., Kandiel, M.M., Sosa, G.A., Abou El-Roos, M.E., Abdel-Ghaffar, A.E., El Azab, A.S. (2011). Benha Effect of $\mathrm{GnRH}$ analogue on libido and semen characteristics of puberal buffalo bulls. Veterinary Medical Journal, 1, 28-34.

Kotani, M., Detheux, M., Vandenbogaerde, A., Communi, D., et al. (2001). The Metastasis Suppressor Gene KiSS-1 Encodes Kisspeptins, the Natural Ligands of the Orphan G Protein-coupled Receptor GPR54. Journal of Biological Chemistry, 276, 3463134636 .

Lee, D.K., Nguyen, T., O’Neill, G.P., Cheng, R., et al. (1999). Discovery of a receptor related to the galanin receptors. FEBS Letters, 446, 103-107.

Silveira L.G., Tusset C., Latronico A.C. (2010). Impact of mutations in kisspeptin and neurokinin $\mathrm{B}$ signaling pathways on human reproduction. Brain Research, 1364, 72-80.

Meyer-Lindenberg, A., Domes, G., Kirsch, P., \& Heinrichs, M. (2011). Oxytocin and vasopressin in the human brain: Social neuropeptides for translational medicine. Nature Reviews Neuroscience, 12, 524-538.

Pineda, R., Plaisier, F., Millar, R.P., \& Ludwig, M. (2017). Amygdala kisspeptin neurons: putative mediators of olfactory control of the gonadotropic axis. Neuroendocrinology, 104, 223238 .

Sieme, H., Troedsson, M.H., Weinrich, S., \& Klug, E. (2004). Influence of exogenous GnRH on sexual behavior and frozen/thawed semen viability in stallions during the non-breeding season. Theriogenology, 61(1), 159-171.

Stephens, S.B., \& Kauffman, A.S. (2017). Regulation and possible functions of kisspeptin in the medial amygdale. Frontiers in Endocrinology (Lausanne), 8, 191-198.

Tissen, I., Kurbanov, R., Hohlov, K., Lebedev, A., et al. (2019). OX1R antagonist SB408124 and extrahypothalamic CRF in rats after psychotraumatic exposure. Georgian Medical News 5(290): 127-131.

Wolfe, A., \& Hussain, M.A. (2018). The Emerging Role(s) for Kisspeptin in Metabolism in Mammals. Frontiers in Endocrinology (Lausanne), 9, 184-189. 